\title{
Moving around efficiently: Energy and transportation
}

\author{
L. J. F. HERMANS
}

Huygens Laboratory, Leiden University - P.O. Box 9504, 2300 RA Leiden, The Netherlands

\begin{abstract}
Summary. - Worldwide, transportation takes almost $20 \%$ of the total energy use, and more than half of the oil consumption. By far the largest part is used by cars powered by internal combustion engines. The reason is simple: oil and gasoline are ideal energy carriers for transportation, since their energy density is extremely high. However, in terms of energy efficiency the internal combustion engine has a poor performance: about $25 \%$ only. How does this compare with electric cars? What are the alternative transportation systems and their efficiencies anyway? In this lecture we will analyse the efficiency of various transport systems, using elementary physics principles. We will look at cars, buses, trains and TGVs, ships, aircraft and zeppelins. Also the efficiency of human powered vehicles will be considered. Special attention is given to future mobile energy carriers like hydrogen, batteries and super capacitors.
\end{abstract}

\section{Transportation and energy}

It may have gone unnoticed by many of us, but moving around has probably become the leading item on our personal energy bills. This is not only because gasoline is heavily taxed: Also in terms of energy, the average family car may be the chief private energy user in many developed countries [1]. For example, if a family drives an average of $20000 \mathrm{~km}$ annually, it consumes ca. 1400 litres of gasoline. In terms of energy use, this is about the same as the $1600 \mathrm{~m}^{3}$ of natural gas consumed annually by the average Dutch household.

So let us look at how we travel. In most developed countries, the average resident uses the car as his or her primary mode of transport. In the Netherlands, for example, 
the average person travels a total of $32 \mathrm{~km}$ per day, of which $25 \mathrm{~km}$ is by car, $3.6 \mathrm{~km}$ by public transport and 2.5 by bicycle (data 2007). In rapidly developing countries like China, the use of cars may still be moderate, but automobile sales are soaring.

It is, therefore, a good idea to look first at the automobile. How efficient is it? Can we improve it? If so, how?

\section{1. - Cars}

In most countries, the largest proportion of car travel is on horizontal roads. This means that it does not involve much climbing and descending, and, since the two compensate one another to a large extent anyway, let us focus on flat roads. First, we obviously need energy when we accelerate. The energy needed to reach speed $v$ is $\frac{1}{2} m v^{2}$. This means that accelerating to $100 \mathrm{~km} / \mathrm{h}$ takes 4 times as much energy as accelerating to $50 \mathrm{~km} / \mathrm{h}$. This is good to keep in mind whenever we notice the traffic light turn yellow in the distance. If we proceed carefully we may be able to avoid braking and having to accelerate again. Anticipation is the keyword here.

How much fuel does an extra full stop take? If we do the calculations we discover that, roughly speaking, accelerating from 0 to $100 \mathrm{~km} / \mathrm{h}$ takes as much fuel as driving $1 \mathrm{~km}$ on a highway. Incidentally, for a train this would be about $15 \mathrm{~km}$. This is because a train is relatively heavy and is pretty economical once in motion. The lesson is that trains perform well provided that they do not stop too frequently, unless they recover the braking energy.

Since gasoline (or diesel, or whatever energy resource) is consumed primarily on the highway, let us look at this situation and find out what exactly determines energy use. When we drive at constant speed, our car has to cope with a certain amount of resistance. In fact, the engine has to push the car with exactly the same force that is needed to overcome that resistance. And it is precisely the resistance that determines the fuel consumption, as we will see later.

What is that resistance we have to cope with? There are two forms of resistance, and we will discuss them separately.

1`1. Rolling resistance. - The ball bearings do not really play much of a role when it comes to the rolling resistance of a car. Rolling resistance is almost entirely caused by the deformation of the tires on the road. That may seem odd: Is rubber not elastic, and does it not bounce back nicely into its original form after it is compressed?

That is indeed true, but the process of compression and expansion does take some energy. This is because the force necessary to compress rubber is greater than the "pushback force" that the tire delivers when it expands (see Box 1). The difference between the two - the net energy - is converted into heat. You can feel how warm the tires get after you drive on a highway for a while! The resulting resistance from all this - the rolling resistance, or rolling friction - is proportional to the weight of the car. It is, in fact, a fixed percentage of that weight, given a certain type of tires at a certain tire pressure. That percentage is called $C_{\mathrm{r}}$, the "rolling resistance coefficient". 


\section{LNES2012}

What $i s$ the value of this $C_{\mathrm{r}}$ ? Could it be around 1 or 0.1 ? These high values cannot be right, and here is why. Suppose our car is parked on a slope, and we release the brakes. How much of a slope do we need for the car to start rolling? It turns out that a slope of about $1 \%$ is enough. What is the force that pushes the car forward on such a slope? Let us look at the weight of the car (which points in the vertical direction) on this sloping road. What we need is its component parallel to the road. We find that this component is $1 \%$ of the car's weight in this case. That is the force which pushes the car forward. So, if that is enough to overcome its rolling resistance, the value of $C_{\mathrm{r}}$ must be ca. 0.01. And sure enough, it is - at least if the tire pressure is right. It is only logical that $C_{\mathrm{r}}$ increases as the tire pressure decreases, because the whole story boils down to the deformation of the tire. It turns out that the rolling resistance increases by about $5 \%$ if the pressure is decreased by $10 \%$ [2].

The value of $C_{\mathrm{r}}$ varies for different tires and road surfaces. In this respect concrete performs best. It does not give way at all and consequently has a somewhat lower resistance than asphalt, which is just a bit softer.

For the average car, a reasonably precise value for $C_{\mathrm{r}}$ is 0.010 . But, for modern tires, it is already a bit lower at 0.009 . Future figures of 0.006 seem plausible.

It is important to note that speed does not play a role here. The rolling resistance is, for all practical purposes, independent of speed.

1`2. Air resistance ("drag"). - The air resistance, or drag, behaves differently. It goes up with the square of the speed. We could guess that from experience: If we stick our hand out the window at $100 \mathrm{~km} / \mathrm{h}$, the force we feel is far larger than at $50 \mathrm{~km} / \mathrm{h}$. It is 4 times as large, to be precise.

Furthermore, the air resistance is proportional to the density of the air. This means that the air resistance increases with increasing atmospheric pressure. It also means that, in the heat of the summer, the air resistance is lower than in the winter, given a certain atmospheric pressure. Analogously, also the thinner air at higher altitudes reduces drag. This also holds for bicycles and speed skaters: breaking a speed record is easier at higher altitudes.

Another factor that determines the drag is the size of the car, or - more precisely - the frontal area. Low and narrow cars have less air resistance than high and wide ones.

Finally, the air resistance is proportional to the famous drag coefficient $C_{\mathrm{d}}$, which is determined by how streamlined the car is. While the value of $C_{\mathrm{d}}$ can be as high as 1 for clumsy objects that are not streamlined at all, it can go down to below 0.3 for some late-model cars.

Why are rolling resistance and air resistance so important? It is because they have a direct influence on fuel consumption. Together, they comprise the total resistance that a car undergoes when it is driven along a horizontal road. This is equal to the force that the engine must continuously produce to maintain a constant speed. The interesting point is that this force is equivalent to the work done-or the energy used-per unit distance. And this can be directly translated into an automobile's energy consumption (see Box 2). 


\section{Box 1. Rolling resistance and air resistance}

The rolling resistance $F_{\mathrm{r}}$ is written as

$$
F_{\mathrm{r}}=C_{\mathrm{r}} \times m g
$$

with $C_{\mathrm{r}}$ being the rolling resistance coefficient, $m$ the mass and $g$ the acceleration due to gravity. This resistance is mainly due to the fact that the force needed to compress rubber is larger than the force which is delivered by the rubber as it tries to bounce back to its original form (in terms of physics: the closed integral $F \cdot \mathrm{d} S$ is not equal to zero). The energy "lost" in this process is released as heat.

The air resistance or "drag" $F_{\mathrm{d}}$ is proportional to the square of the speed $v$. We may derive directly from Bernoulli's law $\left(p+\frac{1}{2} \rho v^{2}=\right.$ const, where $p$ is the pressure and $\rho$ the mass density of air) that the pressure right in front of a flat plate, where $v=0$, must be equal to $\frac{1}{2} \rho v^{2}$. Consequently, the force on such a plate is $A \times \frac{1}{2} \rho v^{2}$ where $A$ is the area of the plate. However, most objects have some level of streamlining, which reduces that force, or resistance. This is expressed in the "drag coefficient" $C_{\mathrm{d}}$. So, the air resistance on an object with a frontal area of $A$ becomes

$$
F_{\mathrm{d}}=C_{\mathrm{d}} \times A \times \frac{1}{2} \rho v^{2} .
$$

The value of $C_{\mathrm{d}}$ is ca. 0.25 for late-model cars. The lower limit for the ideally streamlined vehicle is 0.05 . Although the value of $C_{\mathrm{d}}$ is not quite independent of speed, we may consider it as a constant for the relevant speed range.

\section{Box 2. From resistance to fuel}

Figure 1 shows the behaviour of rolling resistance and air resistance (or drag) as speed increases, for a relatively light and poorly streamlined car. The equations for the two kinds of resistance are given in the Box 1. The values used in this figure are: $m=1000 \mathrm{~kg} ; C_{\mathrm{r}}=0.01 ; C_{\mathrm{d}}=0.4 ; A=2 \mathrm{~m}^{2}$.

We notice that for this car, the two types of resistance are equal at $50 \mathrm{~km} / \mathrm{h}$.

For a heavier and/or more-streamlined car, the two curves cross at a higher speed. Incidentally, for a bicyclist, that crossing point is at ca. $15 \mathrm{~km} / \mathrm{h}$.

Note that the unit on the vertical axis is the unit of force: newton. This is a direct measure of energy consumption. From Work = Force times Distance, it follows that Force $=$ Work per unit distance, i.e., $1 \mathrm{~N}=1 \mathrm{~J} / \mathrm{m}$. At $100 \mathrm{~km} / \mathrm{h}$ for example, we find from the graph that for this car it is ca. 500 newtons, or 500 joules per metre, or 500 kilojoules per $\mathrm{km}$.

But this is the mechanical energy. At an estimated engine efficiency of $20 \%$, this translates into a total energy use of $2500 \mathrm{~kJ} / \mathrm{km}$. Because oil and gasoline have a combustion value of about $40000 \mathrm{~kJ}$ per $\mathrm{kg}$, this amounts to ca. $6.3 \mathrm{~kg}$ per $100 \mathrm{~km}$, or a fuel consumption rate of 7 litres per $100 \mathrm{~km}$. 


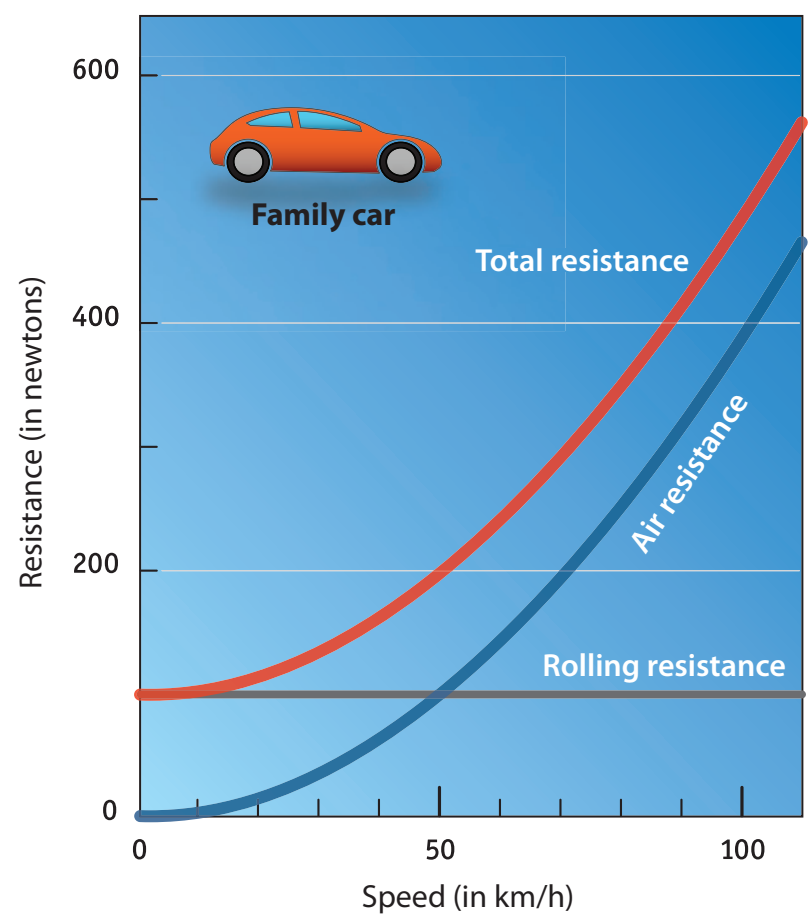

Fig. 1. - The resistance that a car experiences increases dramatically at higher speeds, due to the rapidly increasing air resistance or drag (blue curve). This increases fuel consumption at higher speeds. The figure corresponds to a car with a mass of $1000 \mathrm{~kg}$, a rolling resistance coefficient of $C_{\mathrm{r}}=0.01$, a drag coefficient $C_{\mathrm{d}}=0.4$ and a frontal area $A=2 \mathrm{~m}^{2}$.

To assess the influence of the two types of resistance on the fuel consumption separately, we need to know their relative magnitude. The two are shown for a mid-sized model car in fig. 1. We notice that, when we drive through residential areas at lower speeds (below $50 \mathrm{~km} / \mathrm{h}$ ), the rolling resistance is dominant. It is clearly an advantage in this situation to have a light car (especially since it uses less energy during the frequent stop-and-go cycles).

Things change on the highway, however. Here air resistance is dominant. Now it is more important to have a small car in terms of its frontal area: low and narrow. Moreover, streamlining is essential here. So, driving with your windows open or carrying stuff on the roof is not particularly efficient: it can actually increase fuel consumption dramatically. Since the air resistance increases with the speed squared, driving fast does consume more fuel.

Fortunately, things are not as bad as suggested by the steeply rising curve. This is because the efficiency of an engine increases at higher speeds, since it has to work harder (the efficiency is zero when the engine is idling!). This effect partly compensates for the steep increase in air resistance. But driving fast, in general, remains inefficient. 


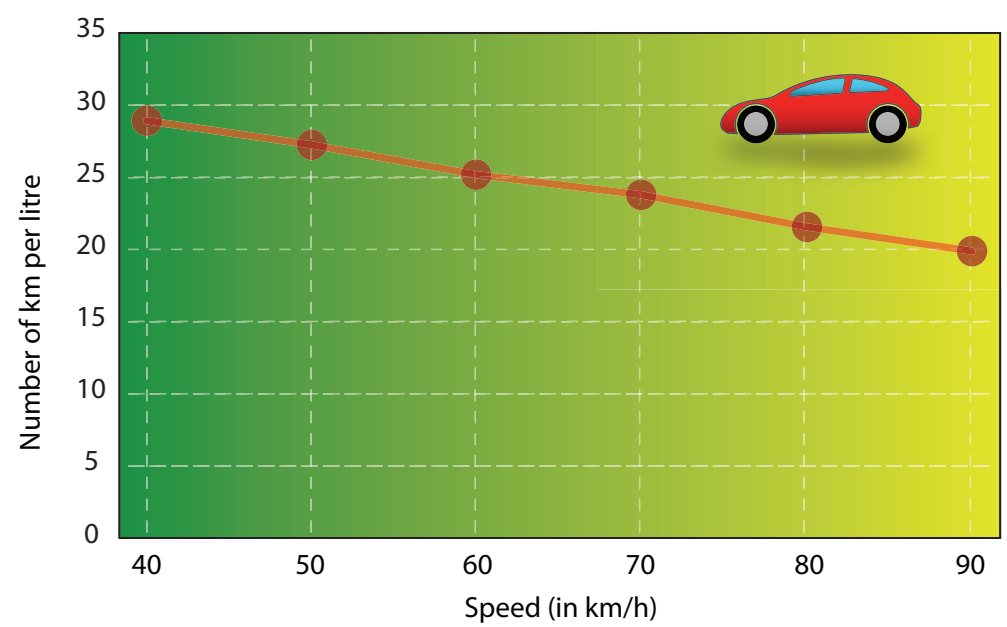

Fig. 2. - Fuel efficiency in terms of number of kilometres per litre for speeds between 40 and $90 \mathrm{~km} / \mathrm{h}$ in fifth gear (Toyota Yaris, courtesy of Herbert Blankesteijn).

Therefore, some sort of speed limit may be a good idea after all, if we consider energy use.

An experimental illustration of how fuel consumption is dependent on speed is highlighted in fig. 2. With decreasing speed and while driving in fifth gear, an efficiency of $29 \mathrm{~km} / \mathrm{l}$ of gasoline was achieved, compared to $20 \mathrm{~km} / \mathrm{l}$ at $90 \mathrm{~km} / \mathrm{h}$.

Obviously, the results will vary for different cars. But the trend remains the same: it pays off to watch our speed. Moreover, we must aim for high engine efficiency. In this case, this was achieved by using fifth gear throughout, even at $40 \mathrm{~km} / \mathrm{h}$.

13. The hybrid car. - It does not sound particularly logical that in order to increase efficiency we equip a car with two engines: an ordinary internal combustion engine and an electric motor. Yet this is indeed the case with a hybrid car. It derives its energy exclusively from gasoline or diesel, so all it does is use this energy more efficiently than an ordinary car. How does it achieve this?

The secret is that its electric motor - in combination with a relatively large batterymakes driving in the city, with its frequent stop-and-go cycles, much more efficient than an ordinary car. At a traffic light, the motor simply turns off; it does not idle like the engine of an ordinary car. Furthermore, it recovers its braking energy by converting it into electricity that recharges the battery. In an ordinary car, that energy is lost in the form of heat in the brakes. So, all of a sudden, driving in the city has become much more efficient.

On the highway, this advantage disappears. Moreover, the battery has a relatively short range and the car must revert to running on gasoline or diesel, just like a "normal" car. This means that, for long-distance travel, a "normal" car with the same amount of streamlining is just as efficient. 
Since the electric motor may be used in conjunction with a normal engine for a short time, to up a hill or overtake another car, it does not hurt to have a smaller internal combustion engine than you would normally find in such a car. This can further enhance engine efficiency, since the efficiency increases when the engine "has to work harder".

In conclusion, the advantage of a hybrid is mainly evident in the city. So, it may be a good idea for taxis to switch to hybrid cars. Not only would that make driving more economical, it would also reduce air pollution in the city.

1*4. The plug-in hybrid and the all-electric car. - The hybrid car discussed above still gets all of its energy from fossil fuel. We can now go a step further and really drive electrically. For long-distance travel this is not yet a practical option, since current battery performances keep us from having enough energy on board (see sect. $5 \cdot 2$ ).

An intermediate option is the "plug-in hybrid". This enables us to drive on electricity drawn, for example, from the power outlet in our own homes. But if the batteries are running low, we can still cover a reasonable distance by switching to gasoline. The charging can be done at selected times when electricity consumption is low (and cheap), for example at night. Alternatively, if solar electricity is used, the batteries can be charged in the middle of the day during periods of maximum sunshine.

The all-electric car is currently an option for short-distance travel only. Its range (typically $150 \mathrm{~km}$ ) may be sufficient for most commuter traffic. If and when battery development improves, cars may drive electrically for distances comparable to those commonly covered by current combustion-engine cars.

Obviously, the question arises whether the electric car is more energy-efficient than the traditional car running on fossil fuels. To compare the two, we must compare the efficiency of an internal combustion car engine (20\% on average) with electricity generation (note that the efficiency of an electric motor is close to 100\%). If we use a power plant fuelled by oil or natural gas, a net efficiency of $35 \%$ is a reasonable figure. So, if losses in the battery-charging process and in the electric motor are small, the electric car would prevail. The advantage is even larger when we consider the lighter weight of the electric motor compared to the internal-combustion engine, plus the fact that an electric car is more efficient in city traffic with its many stop-and-go cycles, as pointed out above. However, energy losses in the charge/discharge cycles can largely offset these advantages.

Electric cars may also be powered by electricity from fuel cells, which are addressed in sect. $5 \cdot 1$.

\section{2. - Buses and trains}

$2 \cdot 1$. Buses. - Buses and cars have in common that they both use rubber tires. Therefore, the rolling resistance coefficients should be similar, but the rolling resistance itself is for a bus much larger because of its weight. For a fair comparison, we should take the rolling resistance per seat. If we do that, we discover that cars and buses are quite comparable (see table I). In other words, if we assume that both have a $100 \%$ passenger load factor, cars and buses should have almost the same energy use rates per person at low speeds. 
TABLE I. - The approximate values for the quantities that determine the energy use of cars, buses and trains. The figures for rolling resistance and air resistance are calculated per seat. These numbers thus provide a direct comparison, if we assume an equal passenger load factor (see also table II).

\begin{tabular}{|c|c|c|c|c|c|c|}
\hline & $\begin{array}{l}\text { Mass } \\
\text { per } \\
\text { seat }\end{array}$ & $C_{\mathrm{r}}$ & $\begin{array}{l}\text { Rolling } \\
\text { resistance } \\
\text { compared } \\
\text { to a car }\end{array}$ & $\begin{array}{l}\text { Frontal } \\
\text { area } \\
\text { per seat }\end{array}$ & $C_{\mathrm{d}}$ & $\begin{array}{l}\text { Air } \\
\text { resistance } \\
\text { compared } \\
\text { to a car }\end{array}$ \\
\hline & $(\mathrm{kg})$ & & & $\left(\mathrm{m}^{2}\right)$ & & \\
\hline Car & 300 & 0.01 & & 0.5 & 0.4 & \\
\hline Bus & 300 & 0.01 & 1 & 0.15 & 0.7 & 0.5 \\
\hline $\begin{array}{l}\text { Train } \\
\text { (double-decker) }\end{array}$ & 600 & 0.0015 & 0.35 & 0.025 & 0.8 & 0.1 \\
\hline
\end{tabular}

However, things change at higher speeds, when air resistance, or drag, is more prevalent. Granted, the bus has a larger frontal area and less streamlining than most cars, but this is compensated for by the large number of passengers a bus can transport. The result is that a bus has only half the drag per passenger compared to a car. So, at higher speeds the bus would beat a car by a factor of 2 , as seen in table I.

Experimental data for buses. - An average bus for 50 passengers consumes about 1 litre of diesel every $3.5 \mathrm{~km}$. This amounts to 175 passenger-kilometres per litre (the number of passenger-kilometres is the number of passengers multiplied by the number of $\mathrm{km}$ travelled). By contrast, a typical diesel car with 4 people on board and travelling at the maximum bus speed limit may reach 80 passenger-kilometres per litre. This, indeed, means that the car is only half as efficient as a long-distance bus.

2.2. Trains. - Trains are a lot like buses if we consider total air resistance. However, trains carry a much larger number of passengers than buses do. So, if we consider the air resistance per seat, the train gains a large advantage (see table I). It beats buses by a factor of 2 and cars by a factor of 10 .

Another big difference is revealed in the rolling resistance. Trains have steel wheels and run on steel rails. Therefore, the rolling resistance coefficient is much smaller. It may not be quite as low as one would expect from the stiffness of steel. This is caused by non-ideal wheel-rail contact that causes some extra friction, and/or by poor track maintenance. Reasonable figures for $C_{\mathrm{r}}$ range from 0.0015 to 0.0020 . This is still much lower than figures for rubber tires on roads. This advantage is partially offset by the relatively large weight of a train, but the rolling resistance of trains per seat remains about 3 times lower (see table I). 
So, trains beat buses and cars especially at speeds at which air resistance is greater than rolling resistance. For trains, the two resistances are equal at around 70 to $100 \mathrm{~km} / \mathrm{h}$, depending on the type of train. Remember that for cars this happens at a somewhat lower speed, ca. 50 to $70 \mathrm{~km} / \mathrm{h}$, again depending on the type of vehicle.

Stopping and accelerating has not yet been taken into account. Trains are relatively heavy, so accelerating is rather costly. Since cruising is relatively efficient, a train can cruise for quite a distance and use the same energy as needed for accelerating to cruising speed. If we work it out for the train used in table I, which consists of four double-decker cars, we find that this distance is ca. $15 \mathrm{~km}$. For a car, this figure is only ca. $1 \mathrm{~km}$. The conclusion here is that trains are efficient especially at longer distances. The more they stop the less efficient they become, unless the braking energy is recovered (a technique that is being used more and more frequently).

During the winter, trains have to be heated, just like cars. But, unlike cars powered by internal combustion engines, they do not have the waste heat to recycle. Instead, they use electric heating, which can substantially reduce a train's energy efficiency.

Experimental data for trains. - A double-decker train consisting of 4 cars (372 seats in total, 254 tons) turns out to have an energy-efficiency of 158 passenger-km per litre of gasoline, if converted to electricity. A $100 \%$ load factor and an average of $14 \mathrm{~km}$ between stops has been assumed. This is about three times as efficient as a full car, which reaches about $56 \mathrm{~km} /$ litre, assuming four occupants and an average of $14 \mathrm{~km}$ per litre.

The advantage of trains increases at longer distances. For $50 \mathrm{~km}$ between stops, the energy-efficiency increases to 260 passenger-km per litre. Again, it is assumed that braking energy is simply lost.

23. TGV (train à grande vitesse), High-speed trains, MagLev (magnetic levitation). - All these trains move at very high speeds through air at ambient pressure, so they are bound to be inefficient. The reason is that the air resistance increases with the speed squared, just like for cars. So, twice as fast means four times the energy.

The rolling resistance becomes negligible at speeds above $300 \mathrm{~km} / \mathrm{h}$ approximately. Therefore, magnetic-levitation trains (which have no rolling resistance) offer barely any improvement in terms of energy efficiency.

So, one would not expect high-speed rail travel to be very efficient. Despite its excellent streamlining (low $C_{\mathrm{d}}$ ) we should expect that a TGV, travelling more than twice as fast as a normal long-distance train, will use about four times the energy.

Experimental data for TGV. - In practice, the TGV uses roughly five times as much energy as an ordinary long-distance train if this is expressed in terms of gasoline consumed (as we did with the trains above). It achieves about 50 passenger-km per litre. This confirms our calculations above, where we expected it to be roughly a factor of 4 worse than a regular long-distance train. One aspect that may improve TGV performance in practice is the relatively high occupancy rate. 


\section{3. - Aircraft}

The fuel consumption of planes per passenger-km depends on a number of variables. Is the plane full? What type of plane is it? How close are the seats to one another? Is the plane carrying cargo in addition to passengers? Is it a long-distance flight?

The last question has an interesting answer. Obviously, short flights are not very efficient, because of the relatively large amounts of fuel used for take-off and landing. So, longer flights should be more efficient. But wait, very long flights require extra heavy loads of fuel. Indeed, flights above, say, $5000 \mathrm{~km}$ become less efficient, since there are fewer passengers on board because of the weight of the extra fuel. We can estimate this by using a rule of thumb: an aircraft at cruising altitude consumes almost $10 \mathrm{~cm}^{3}$ of fuel per second per seat, irrespective of the type of aircraft. For a flight of $5000 \mathrm{~km}$ that takes 6 hours, we can expect fuel consumption to be $6 \times 3600 \times 0.01$ litres per passenger. This is 216 litres, or the equivalent of the weight of 2 passengers!

To estimate fuel consumption, let us again use the rule of thumb that the fuel consumption for each passenger is almost $10 \mathrm{~cm}^{3}$ per second. This number was fairly accurate for many different types of planes during the 1980s, but it has been gradually decreasing somewhat as planes are becoming more efficient. Even so, it is convenient to keep this in mind as a rule of thumb.

It follows that flying for one hour consumes ca. 36 litres of kerosene per passenger. Since we cover almost $1000 \mathrm{~km}$ during an hour, the consumption should be about 3.6 litres per $100 \mathrm{~km}$, or $28 \mathrm{~km}$ per litre per passenger. This is equivalent to the fuel efficiency of a car consuming $14 \mathrm{~km}$ per litre with 2 occupants.

The conclusion is that a full plane is (per $\mathrm{km}$ and per passenger) roughly as efficient as a half-full car. Since both planes and cars are becoming increasingly efficient, this rule of thumb may hold for many years to come.

There are some factors that complicate matter, however. Take cargo. Most planes carry a lot more cargo than just passengers' luggage. This makes it difficult to calculate efficiency with any precision (see also experimental data for aircraft below).

It may come as a surprise that planes are relatively efficient, given the fact that the air resistance increases steeply with speed. Why is that? We should bear in mind, first, that the cruising altitude for planes is at (or even above) $10 \mathrm{~km}$. The air density is only one-quarter of the air at sea level. Furthermore, planes have excellent streamlining. Last but not least, their dead weight is relatively small. If we compare the total mass of passengers plus luggage plus cargo with an empty aircraft, we find a ratio of ca. 1 to 10 . This is particularly favourable if compared with a passenger ship (see table II).

Experimental data for aircraft. - A long-distance flight by a Boeing 777-200, carrying 260 passengers and $12000 \mathrm{~kg}$ of cargo, consumes about $68000 \mathrm{~kg}$ or 85000 litres of kerosene over a distance of $9000 \mathrm{~km}$. This is 28 passenger-km per litre, which corresponds to the above figures. But we should also consider the cargo. If we assume the above $12000 \mathrm{~kg}$ of cargo to be the equivalent of 120 passengers including their luggage, all of a sudden we have 380 people on board. This would give us 40 passenger-km per litre. The airship is a special case. It is treated in Box 3 . 


\section{Box 3. What about the Zeppelin?}

An airship, or Zeppelin (named after the German count Ferdinand Graf von Zeppelin, the inventor of the airship) can stay up in the air without using any energy. This sounds extremely efficient. So does this not offer the ultimate energy-efficient form of transport?

Well, as long as the Zeppelin is just hanging around in the air, this may be true. Even if it is used as a crane, to hoist things and transport them over short distances, it may be an efficient piece of equipment. But as soon as it starts moving, this all changes.

For example, could a Zeppelin beat a plane on a trip across the Atlantic, if we look at energy use?

Let us make a back-of-the envelope calculation. We only need to consider air resistance here, which increases with the speed squared. A speed of $100 \mathrm{~km} / \mathrm{h}$ seems to be a minimum (just think of headwind!). At that speed, the air resistance is gigantic for such a large object moving through the air. We have to assume air density at approximately sea level, because the airship would not have enough lift at high altitude with its lower air pressure.

We may take the dimensions of the Hindenburg, the airship that made quite some history when it tried to land in New Jersey, USA, back in 1937. It was carrying ca. 100 passengers and had a diameter of 41 metres. This yields a frontal area of $13 \mathrm{~m}^{2}$ per passenger.

Obviously, there is no way that this can compete even with a car, which has a frontal area per passenger of only $0.5 \mathrm{~m}^{2}$. Even if we include the (relatively small) contribution of the rolling resistance of a car and the superior streamlining of an airship, the car would still be some 10 times more efficient than the airship.

We can check our calculations using the Hindenburg's technical data. It had a top speed of $135 \mathrm{~km} / \mathrm{h}$ and its engines had $3560 \mathrm{~kW}$ of total power. If we work it out we discover that, indeed, the car still beats the airship by a factor of 8 .

If compared to a plane, the airship has two drawbacks. First, it has this enormous volume, which creates large amounts of air resistance. Second, the density of the air through which it moves is larger by a factor of 4 compared with the air at cruising altitude of a plane.

The conclusion is inevitable. There is no bright future for the airship. Unless we really want to take our time. 
TABLE II. - Energy efficiency in terms of number of passenger-km per litre of fuel, assuming a passenger load factor of $100 \%$ and long-distance travel. For electric vehicles, the electricity is assumed to be generated in an oil-fuelled power plant, and for the bicycle the energy equivalent of food is expressed in litres of oil.

\begin{tabular}{lrrr}
\hline & $\begin{array}{r}\text { Number of } \\
\text { Passengers }\end{array}$ & $\begin{array}{r}\text { Speed } \\
(\mathrm{km} / \mathrm{h})\end{array}$ & $\begin{array}{r}\text { Energy efficiency } \\
\text { (passenger-km/litre) }\end{array}$ \\
\hline Bicycle & 1 & 20 & 500 \\
Electric bicycle & 1 & 20 & 400 \\
Train & 250 & 130 & 250 \\
Bus & 50 & 100 & 170 \\
Car & 4 & 100 & 60 \\
TGV & 377 & 300 & 50 \\
Aircraft & 400 & 900 & $30^{\mathrm{a}}$ \\
Passenger ship & 2000 & 50 & 4 \\
\hline
\end{tabular}

${ }^{\mathrm{a}}$ Modern planes like the A380 may achieve 35. (Source: Singapore Airlines, 2008.)

Comparison. - How do various means of transportation compare, if we consider energy use? Table II quotes some approximate values.

The poor performance of the passenger ship is striking, especially in view of its low speed. The reason is not only that it has to move through water, the density of which is a factor of $10^{3}$ greater than air at sea level. More importantly, the dead weight of a passenger ship - or a cruise ship - is enormous. Unlike other means of transportation, these ships have been designed to spend a lot of time at sea. Therefore, they have dining rooms, shops, ballrooms, even swimming pools and the like. In fact, these ships are floating villages. For example, take the relatively modern Queen Elisabeth 2. This ship is 345 metres long, has a mass of 70000 tons and carries 1900 passengers. If we include their baggage the passengers may weigh in at ca. 200 tons. This is only about $0.3 \%$ of the ship's total weight. The passengers on an aircraft comprise ca. $10 \%$ of its total weight, as mentioned above.

Care should be taken not to generalise the poor performance of passenger ships to ships in general. The load carried by cargo-boats and oil tankers is usually very large compared to their own weight. Therefore, their energy efficiency is very good.

\section{4. - The bicycle}

Mankind managed to improve its transport efficiency by a factor of 4 by inventing the bicycle. Walking is already fairly efficient compared to flying and other modes of transport, including those in the animal world. But cycling beats every mode of transport, if one measures the amount of energy per $\mathrm{kg}$ of displaced mass over a fixed distance [3].

Just how much energy does it take to ride a bicycle? There is an easy way to calculate this. The power that it takes to ride a bike is quite comparable to climbing stairs, which 
requires ca. $100 \mathrm{~W}$. Now imagine the following experiment in which we ride a bicycle for 24 hours continuously. The above $100 \mathrm{~W}$ of mechanical energy means that total energy use for cycling is $400 \mathrm{~W}$, given a muscle efficiency of $25 \%$. A continuous energy use of $400 \mathrm{~W}$ corresponds to one litre of oil per day. So, if we would cycle for a day, we would use the equivalent of 1 litre of oil for a 24 hour bike ride. In those 24 hours, we cover a distance of $24 \times 20 \mathrm{~km}$, approximately $500 \mathrm{~km}$.

Conclusion: A bicyclist consumes roughly "1 litre per $500 \mathrm{~km}$ ".

That is enormously efficient. But there is a catch. We do not cycle on oil or gasoline, but on bread, milk, steaks, and cheese. All of this food takes a lot more energy to produce and deliver to our home than its own energy content represents. Take milk, for example. The cows have to eat, they have to be milked (electrically), and the milk must be cooled down, transported, heated to be pasteurized, cooled again, and transported again. If you add it up, one litre of milk may cost half a litre of oil before it gets to your kitchen table. Much the same can be said regarding the rest of the food as well. So, while bicycling is wonderful and very healthy, if we want to save energy we might be better off buying a light motorcycle.

4.1. Rolling resistance and drag for bicycles. - Let us consider cycling on a horizontal road, so we do not need to fight gravity. The bike itself offers very little mechanical resistance, provided it is in good condition. The ball bearings cause a loss of about $1 \%$ only, a well-oiled chain about $1.5 \%$, the gears ("derailleur") $5 \%$ at most [4]. Once we reach cruising speed, the real forces that we have to compensate for are rolling resistance and air resistance. It is the same as for a car (see fig. 1). But with a bicycle, we are obviously working with different figures.

The rolling resistance coefficient $C_{\mathrm{r}}$ is very comparable to the value we saw earlier for a car, again depending on the tire pressure. Typical figures for standard tires are between $C_{\mathrm{r}}=0.006$ and 0.01 . For racing bikes a typical value is 0.003 .

The air resistance or drag coefficient (the " $C_{\mathrm{d}}$-value") is determined by the streamlining. For a bicyclist sitting upright $C_{\mathrm{d}}$ is about 1 . For a hunched-over racer it is about 0.88 (in this case, the frontal area is also reduced, leading to a double gain). But for a cigar-shaped super bike, the HPV (Human Powered Vehicle), it can be as low as 0.1.

The behaviour of the two resistances for an ordinary city bicycle is analogous to the behaviour shown for a car in fig. 1, except that, for a bicycle, the rolling resistance dominates for speeds up to about $15 \mathrm{~km} / \mathrm{h}$. At higher speeds, the air resistance is dominant. For reaching high speeds, the streamlining is therefore essential, and setting a speed record essentially means reducing air resistance. Super bikes (HPVs) can reach speeds over $100 \mathrm{~km} / \mathrm{h}$, which an ordinary racing cyclist cannot even think of.

As noticed for the case of a car, the total resistance, or force, is a direct measure of energy use per kilometre. At a speed of $20 \mathrm{~km} / \mathrm{h}$, the total resistance for such an ordinary city bike $\left(C_{\mathrm{r}}=0.006 ; m=90 \mathrm{~kg} ; C_{\mathrm{d}}=1.1 ; A=0.50 \mathrm{~m}^{2}\right)$ is found to be 16 newtons. Mechanical energy use therefore is $16 \mathrm{~kJ} / \mathrm{km}$. With a muscle efficiency of $25 \%$, this means a total energy use of $64 \mathrm{~kJ} / \mathrm{km}$. 
Since the energy content of oil or gasoline is $40 \mathrm{MJ} / \mathrm{kg}$, this corresponds to 1.6 gram per $\mathrm{km}$. So our earlier rough estimate of 1 litre per $500 \mathrm{~km}$, i.e., 2 grams per $\mathrm{km}$ was fairly accurate after all.

And how much fat would we lose on our bicycle if we do not eat anything extra? If we take the above case and we realise that the energy content of oil and fat are quite close, we conclude that we burn 2 grams of fat by cycling $1 \mathrm{~km}$. So, if we want to slim down by $1 \mathrm{~kg}$ on your bicycle, we find that this takes a distance of some $500 \mathrm{~km}$.

\section{5. - Alternative energy carriers}

After the "fossil-fuel era" alternative energy carriers will have to be used. The most promising candidates are likely to be hydrogen and advanced batteries. Let us have a closer look at both, and include "super capacitors" which have enjoyed a remarkable development lately.

$\mathbf{5}$ 1. Hydrogen as an energy carrier. - The relevant properties of hydrogen are given in table III.

Once electricity is available (for example, by using solar PV panels or wind turbines), hydrogen can be produced by electrolysis. The efficiency of this process is around $80 \%$ for modern equipment. In the future, $\mathrm{H}_{2}$ may be also efficiently produced directly from solar energy by "photo-electrolysis" or "biophotolysis".

Hydrogen's efficiency as a fuel depends on how it is used.

- Hydrogen may be used simply as a fuel for internal combustion engines. However, we must realise that the efficiency will not exceed 20 to $30 \%$, as it is limited by the Carnot efficiency. If we want to use hydrogen to produce mechanical energy, we can do much better:

- Hydrogen can also be used in a fuel cell, which directly converts $\mathrm{H}_{2}$ and $\mathrm{O}_{2}$ into electricity. Remember that an electric motor has an efficiency close to $100 \%$, in contrast to an internal combustion engine. By going directly from fuel to electricity we avoid the inefficient step of converting heat to mechanical energy. An efficiency of $60 \%$ in fuel cell operation has thus far been achieved, which is twice as efficient as the internal combustion engine.

TABLE III. - Properties of molecular hydrogen $\left(\mathrm{H}_{2}\right)$.

\begin{tabular}{|c|c|c|c|}
\hline Heat of combustion $\left(\right.$ higher $^{\mathrm{a}}$ ) & $12.8 \mathrm{MJ} / \mathrm{m}^{3}$ & or & $142 \mathrm{MJ} / \mathrm{kg}$ \\
\hline Heat of combustion $\left(\right.$ lower $^{\mathrm{a}}$ ) & $10.8 \mathrm{MJ} / \mathrm{m}^{3}$ & or & $120 \mathrm{MJ} / \mathrm{kg}$ \\
\hline Density (at $0^{\circ} \mathrm{C}, 1$ bar) & $0.090 \mathrm{~kg} / \mathrm{m}^{3}$ & & \\
\hline Boiling point & $-253^{\circ} \mathrm{C}$ & or & $20.4 \mathrm{~K}$ \\
\hline Density of liquid $\mathrm{H}_{2}$ & $71.0 \mathrm{~kg} / \mathrm{m}^{3}$ & & \\
\hline
\end{tabular}

a This is similar to natural gas. The "higher" heating value includes the heat of condensation of the water vapour; the "lower" value does not. 


\section{LNES2012}

So, a fuel cell offers a useful solution when we need electricity (or mechanical energy, since the two can be efficiently converted into one another).

Storing hydrogen in a car. - Storing hydrogen for mobile applications remains a challenge. This is because, at ambient temperature, hydrogen is a gas, as opposed to petrol or diesel. And for a gas at ordinary temperature and pressure the number density is smaller than it is as a liquid by a factor of roughly one thousand. If we stick to gas at 1 bar, we must think in terms of cubic metres rather than litres, meaning we either have to compress the gas or turn it into a liquid, if we want to store a large amount in a small volume.

We are lucky in one respect. If we consider the combination of hydrogen plus fuel cells as a way to power an electric motor, we achieve an efficiency ca. twice that of an ordinary internal combustion engine. So, in order to be able to drive a certain distance, we need to only store half the energy in the form of hydrogen.

There are currently three ways to store hydrogen in a car in a relatively compact volume.

1. As a gas at high pressure. This requires strong (and thus heavy) containers. To store the energy equivalent of 50 litres of petrol, storage cylinders have a total mass of 300 to $400 \mathrm{~kg}$. Incidentally, the fuel itself has a mass of less than $10 \mathrm{~kg}$ in this case. For city buses, for example, storage is not such a problem. They have more space, weight is less crucial and they return to the garage frequently.

2. As a liquid. The boiling point of $\mathrm{H}_{2}$ is $20.4 \mathrm{~K}$ (see table III). This makes handling, loading and transport cumbersome. Moreover, the tank must be superbly insulated to prevent rapid evaporation. Even super-insulation means a "boil-off" of 1 to $2 \%$ per day. We may compare this to keeping a bottle of water in a $300{ }^{\circ} \mathrm{C}$ environment. Even with excellent insulation (like a thermos bottle) it will inevitably boil down and eventually empty, like a pan of boiling water on a tiny gas pit.

3. Sorbed into a solid. Some metals are capable of absorbing large amounts of hydrogen, even to the extent that the amount of hydrogen per unit volume is larger than in the liquid phase. The flip side of the medal, however, is that the "tank" is very heavy compared to the weight of the hydrogen inside. This is obvious because hydrogen is the lightest of the elements and metals tend to be heavy. An example of a metalhydrogen compound ("metal hydride") is $\mathrm{LaNi}_{5} \mathrm{H}_{6}$, where hydrogen is stored in an alloy of lanthanum and nickel, both heavy metals. If we look up the masses of $\mathrm{La}$ and $\mathrm{Ni}$, we find that the mass ratio of hydrogen to metal is 6 to 432 . But the good news is that $6 \mathrm{~kg}$ of hydrogen enables us to travel some $600 \mathrm{~km}$.

Using metal hydrides requires a temperature-control system that controls absorption and desorption, since this process is very temperature dependent. It is comparable to a fluid's evaporation and condensation process.

Given these complications, we can predict that hydrogen vehicles will, at least in the short run, fill their tanks with hydrogen gas at high pressure (350 to 700 bar). The 700 bar is already being used in Norway, on the HyNor, see below. Carrying liquid hydrogen on board is only practical thus far in exceptional cases, like for racing cars. This is still too 
TABLE IV. - Rough comparison of various mobile energy carriers with energy equivalent of 50 litres of petrol.

\begin{tabular}{lrr}
\hline & $\begin{array}{c}\text { Volume in litres } \\
\text { ("tank" included) }\end{array}$ & $\begin{array}{r}\text { Mass in kg } \\
\text { ("tank" included) }\end{array}$ \\
\hline Petrol & 52 & 60 \\
Hydrogen under high pressure & 300 & 400 \\
Hydrogen, liquid & 100 & 150 \\
Hydrogen as LaNi $\mathrm{H}_{6}$ & 200 & 500 \\
High-tech flywheel & 400 & 1000 \\
Lead batteries & 2000 & 3000 \\
\hline
\end{tabular}

complicated for ordinary cars. Storage of $\mathrm{H}_{2}$ as a hydride in metals on a large scale will, alas, require more research and development (see also table IV).

Hydrogen on the "Hyway"? - Obviously, tanking up with hydrogen along the highway requires a special infrastructure: "gas stations" that deliver hydrogen, with highways that provide hydrogen refuelling called "hyways" for obvious reasons. California began a hydrogen highway network in 2005, primarily to reduce air pollution, aiming to have 50 to 100 operable refuelling stations along the West Coast by 2010. There were only about 30 such filling stations in 2010, with several more under construction. Future development depends on how many hydrogen cars are sold, and vice versa, which implies slow growth. Europe has also several of these projects. For example, Germany, Sweden and Denmark have plans for a system of interconnected hyways. Norway, meanwhile, is building a $580 \mathrm{~km}$ hyway between Oslo and Stavanger (HyNor, or Hydrogen road of Norway).

There is one drawback, however. Spilled hydrogen enters the atmosphere, where it may affect the ozone layer. The precise seriousness has yet to be determined, but there is reason enough (also in view of security) to insist on leak-proof refuelling stations.

We can now compare a few alternative mobile energy carriers that enable us to travel the same distance as 50 litres of petrol (see table IV). Again, we notice that there is no energy carrier as convenient as petrol or diesel. The point is that nothing can beat the energy density of a fuel that is liquid at ambient temperatures. This basically limits us to hydrocarbons having about 10 carbon atoms per molecule, like oil, petrol and diesel. Fuels with shorter carbon chains like propane have vapour pressures that are too high to be very useful. Longer-chain molecules, such as fats, have vapour pressures that are too low. Alcohol may be one of the only alternatives. But alcohol production itself requires energy.

This may add an extra incentive for conserving oil. It is too handy a fuel to simply burn like scrap wood. All alternatives are much less convenient for transportation purposes. 
TABLE V. - Approximate energy densities of batteries and supercapacitors, in $k W h$ per $k g$.

\begin{tabular}{ll}
\hline Lead battery: $(40 \mathrm{Ah} \times 12 \mathrm{~V} \approx 0,5 \mathrm{kWh})$ & $0.03 \mathrm{kWh} / \mathrm{kg}$ \\
NiMH battery & 0.06 \\
Li-ion battery & 0.15 \\
Li-ion polymer battery $(\mathrm{LiPo})$ & 0.20 \\
Supercapacitor & 0.005
\end{tabular}

predicted performance $0.020 \mathrm{kWh} / \mathrm{kg}$; power $2 \mathrm{~kW} / \mathrm{kg}$

5'2. Electricity storage for transportation. - The hybrid and the electric car were both discussed in sect. 1. The basic problems with electric cars are twofold: the batteries are still too heavy and bulky, reducing the range to some $150 \mathrm{~km}$, and "refuelling" still takes too long.

If one compares the refuelling rates of petrol vs. electrical energy, one comes up with some amazing figures. Charging a car battery at a standard $230 \mathrm{~V}$ electric outlet at home may be done at a maximum rate of about $3.5 \mathrm{~kW}$, if we want to prevent the $16 \mathrm{~A}$ fuse from blowing. Just how slow this transfer rate is becomes clear if we compare it to petrol. Refuelling a normal car at a standard service station takes about 100 seconds for 50 litres. The transfer rate is thus 0.5 litres per second or about $18 \mathrm{MJ} / \mathrm{s}$, or $18 \mathrm{MW}$ ! In other words, this is 5000 times faster.

So, the future electric car may need services such as battery exchanges rather than battery recharging. This reminds us of the old days of the stagecoach. The difference is that in those days horses were exchanged, not batteries.

Batteries and supercapacitors. - Storing electrical energy is not easy. Almost all of the current model cars still rely on traditional lead batteries, but they do not have an awful lot of energy. An average 12 volt battery has a charge of $40 \mathrm{Ah}$. Combining the two figures yields $480 \mathrm{Wh}$, or $0.480 \mathrm{kWh}$ of energy. This is the equivalent of a wine glass full of petrol. Taken per $\mathrm{kg}$, this battery contains about $0.03 \mathrm{kWh} / \mathrm{kg}$ of energy only.

The nickel-metal-hydride battery does a much better job. It is relatively cheap, safe and contains $0.06 \mathrm{kWh} / \mathrm{kg}$ of energy, which is twice as good as the lead battery. It is currently used in hybrid cars.

Lithium-ion batteries in mobile phones and laptops perform even better, achieving ca. $0.15 \mathrm{kWh} / \mathrm{kg}$. However, they are relatively expensive, complex and present some safety issues if used in cars. Moreover, the Li-ion battery is not particularly durable as a result of various chemical processes. It looses performance more quickly at higher temperatures and when fully charged. Optimum storage conditions imply lower temperatures with the battery loaded to $50 \%$ of capacity. Useful information is found at: www batteryuniversity . com.

Batteries have problems delivering large amounts of energy quickly, i.e., if they must produce a high power. This is because the chemical processes that form the basis of the storage mechanism react slowly. True electricity storage occurs in capacitors, which 
do not display these problems. They can be charged and discharged extremely quickly. But common capacitors as found in electric appliances are totally useless in storing large amounts of energy. Modern "supercaps" have a much larger capacity. They are extremely well suited for storing the braking energy of a car or a trolley, and subsequently re-delivering it for quick acceleration. They are also called "boostcaps" since they give brief boosts to racing cars. Another advantage is that they can be charged and discharged millions of times without performance loss, in contrast to batteries with a much more limited number of charge/discharge cycles. One drawback, however, is that, while they deliver large amounts of power, they cannot store large amounts of energy. Plus they are still expensive. An overview of energy densities is given in table $\mathrm{V}$.

\section{REFERENCES}

[1] See, e.g., International Energy Agency: www.iea.org/statistics.

[2] Tires and Passenger Vehicle Fuel Economy (National Research Council of the National Academies, Washington, DC) 2006.

[3] Hermans J., Energy Survival Guide (BetaText, Bergen and Leiden University Press, Leiden) 2011, p. 61.

[4] Wilson D. G., Bicycling Science (MIT Press, Cambridge, MA) 2004. 